\title{
Hélio Oiticica y la blanca singularidad simultánea de Newyorkaises ${ }^{1}$
}

\section{Hélio Oiticica and the white simultaneous singularity of Newyorkaises}

\author{
ALVA MARTÍNEZ TEIXEIROa \\ ${ }^{a}$ Universidade de Lisboa, Faculdade de Letras. Portugal. \\ Correo electrónico: alvamteixeiro@campus.ul.pt
}

Este artículo pretende examinar el trabajo del artista y escritor de neo-vanguardia Hélio Oiticica (Rio de Janeiro, 1937-1980), cuya obra fue vista en su época (y también en nuestros días) como una de las posibles vías para construir otro tipo de neo-vanguardia brasileña: más inconveniente y más libertaria que aquella que corresponde a la visión consensual y excluyente de la Neo-vanguardia tout court (o sea, la de los movimientos artísticos y literarios del concretismo y del neo-concretismo).

Así, el artículo pretende, por una parte, ofrecer una visión panorámica de la obra de Hélio Oiticica, evaluando las opciones temáticas y los procedimientos literarios y artísticos del autor.

Además, pretendemos realizar un análisis crítico de las especificidades y las contribuciones de la obra Newyorkaises (Conglomerado), del heterodoxo y rompedor artista carioca, en la confluencia de diversas formas artísticas e hibridaciones genéricas.

Por último, también analizaremos la enciclopedia cultural del pensum literario, plástico y musical que subyace a esta escritura experimental y el modo visualista, (neo) vanguardista y contracultural que lo preside.

Palabras claves: Hélio Oiticica, neo-vanguardia, contracultura, Brasil, escritura.

This article focuses on the work of the neo-avant-garde artist and writer Hélio Oiticica (Rio de Janeiro, 1937-1980), whose work was seen at the time (and nowadays) as one of the possible ways to build another kind of Brazilian Neo-avant-garde and that is at the core of this present study: a different kind of Neo avant-garde that would be more inconvenient and more libertarian than that which corresponded to the consensual and cliquish ideas found in Brazilian Neo-avant-garde tout court (i.e. the concrete and neo-concrete art and literary movements).

\footnotetext{
${ }^{1}$ Este artículo es un resultado parcial del proyecto de investigación Artistas letrados e letrados artistas. Relaçöes entre literatura e artes plásticas na modernidade contemporânea brasileira (ALLA), financiado con fondos de la Fundaçáo para a Ciência e a Tecnologia (FCT) de Portugal, en el ámbito del Centro de Literaturas e Culturas Lusófonas e Europeias de la Universidade de Lisboa (CLEPUL).
} 
In this respect, the article aims, on the one hand, to give an overview of Hélio Oiticica's work, evaluating thematic choices and literary and artistic procedures.

Also, I carry out an evaluative analysis of the specificities and the contributions of this Rio de Janeiro artist's unorthodox and groundbreaking Newyorkaises (Conglomerado), at the crossroads of different art forms and generic hybridization. Finally, I also examine the cultural encyclopaedia of the literary, plastic and musical pensum that lies behind this experimental writing and the visualist, (neo)avantgardist and countercultural mode it obeys.

Key words: Hélio Oiticica, neo-avant-garde, counterculture, Brazil, writing.

Il n'y a pas de solutions parce qu'il n'y a pas de problème [Marcel Duchamp]

Durante sus cuarenta y tres años de vida, Hélio Oiticica (1937-1980) fue el artista pionero y fundamental de la vanguardia brasileña de los años cincuenta, sesenta y setenta. Dejó un doble legado experiencial-interventivo y plástico-escritural de tal importancia y fuerza que sólo se puede explicar por su empeño inventivamente creativo y por su incansable - y constante - trabajo. De hecho, a diferencia de una no rara actitud brasileńa culturalmente acomodaticia, puede (y debe) ser considerado un genuino in(ter)ventor cultural, un artista plástico esencial y un lúcido creador bifronte, porque él fue también autor de una obra literaria muy interesante e injustamente relegada a un segundo plano.

Oiticica vivió y, por así decirlo, no pasó su vida definitivamente a limpio, pero sí creó y dejó constancia por escrito, a través de un proceso constante de reinvención, de su obra teórico-crítica — más 'auto' que 'exo' crítica — de forma clarificadora y precisa: realizó un registro sistemático y presentó al lector una explicación minuciosa y un inteligente desdoblamiento reflexivo y conceptual —en el sentido etimológico de ex-plicare, o sea, de (re)tirar plica a plica, pliegue a pliegue o doblez a doblez-.

Por lo general, es esa excelente crítica artística, de carácter ensayístico y en las antípodas de cualquier oscura verbosidad, la que se ha privilegiado, relegando a un segundo plano su registro creativo más vitalmente literario y que, tal como su vida, no pasó a limpio; es decir, su escritura más expresiva del deseo y de la locura, del rouge désir y de la folie noire, del arte y de la vida en los márgenes en los que Hélio ensayó y falló más y mejor —en el sentido emblemático de la significativa máxima de Beckett: 'Inténtalo, vuelve a fallar, falla mejor' - .

En otras palabras, al moverse entre lecturas interpretativas, literarias y literales, los estudiosos, estableciendo distinciones entre lo artístico y lo literario y primando la fácil aproximación sobre la esquiva nuance, han escogido del magma escritural de su legado, básicamente, los extraordinarios textos teoréticos y reflexivos presentes en la antología póstuma Aspiro ao grande labirinto. Seleção de textos (1954-1969). Esta antología fue organizada en 1986, basándose en los documentos reunidos en el "Projeto HO", por Luciano Figueiredo, Lygia Pape y Waly Salomão, y presenta escritos en los que, según afirma 
Figueiredo en la "Introduçáo", "el proceso y el universo creativo del artista son demostrados en proposiciones teóricas y [...] poéticas". ${ }^{2}$ En fin, la verdad es que a pesar de esa afirmación, sus diarios o, por así decirlo, cuadernos de bitácora artísticos, además de incluir de modo muy puntual algún fragmento vitalista, apenas presentan, a título excepcional, seis textos (tout court) poético-literarios: por una parte, el extraordinario testimonio cronístico de "LONDOCUMENTO" y el vértigo del aggionamento brasileño del underground en los poemas (para)concretos "SUBTERRÂNIA" y "SUBTERRÂNIA 2" —ambos escritos en Londres en agosto y setiembre de 1969-; por otra parte, la reconstrucción memorialista de la noche negra del evento artístico realizado en agosto de 1968 en el vertedero carioca de Flamengo, presente en la "APOCALIPOPÓTESE", y los dos textos obscuros, teñidos de una especie de esquizofrenia sensitiva, del "AUTO I" y "Tuiuti paradiso paradise paraiso sorriso ou cósmico anseio..." - que forman parte de los textos que Oiticica describió en una carta de 1969 como "cuentos en un lenguaje inventado, y autos, que serían una biografía inventada también" de octubre y los otros dos de noviembre de 1969.

A la búsqueda de un más apurado sentido de la obra en la vida del autor, no nos resistimos a destacar la importancia de un uso comedido de los elementos biográficointencionales —a veces más literaturizados de lo que, por así decir, vividos—; una importancia afirmada por el carácter inseparable del par vida-obra en el desarrollo de una mejor comprensión de algunos aspectos de la creatividad oiticiquiana. Para dar sólo un ejemplo, mencionemos el anarquismo de origen familiar y la ética libertina de carácter individualista en los que, ciertamente, se basa su peculiar posicionamiento político. Aquel posicionamiento que, al contrario de las conocidas 'patrullas ideológicas' de la época, inicialmente, interioriza en parte una liberada actitud anarquizante, haciendo que, poco a poco, Hélio adopte y actualice una postura anarcorromántica y libertina para oponerse al poder, a los poderes y a las directrices del buen comportamiento, acabando por identificar el anarquismo, más allá de lo marginal, tanto en los actos creativos provocadores situacionistas, como en la utopía inmediata de los hippies.

Pero, en fin, retomando el análisis de la referida antología, podemos observar fácilmente que es tendenciosísima - tal y como las concebía el poeta y pintor surrealista portugués Mário Cesariny_- porque ignora los 'escritos babilónicos' del 'Libro' o 'me libro' — según la expresión de Fred Coelho- que Oiticica, en una actitud obsesiva y fordista, creó durante su productiva estancia, de 1971 a 1978, en una Nueva York brutalista que el autor rebautizó como Babilonia, donde vivió en la Second Avenue, con una bolsa de la fundación Guggenheim, y, a continuación, en Christopher Street, en el Village. Son escritos que sólo fueron publicados en formato libro hace un lustro, por la editora carioca Beco do Azougue.

\footnotetext{
2 "o processo e universo criativos do artista são demonstrados em proposições teóricas e [...] poéticas" (Figueiredo 1986: 5).

3 "contos numa linguagem inventada, e autos, que seriam uma autobiografia inventada também" (Cit. en Braga 2007: 16).
} 
En esa edición, los textos fueron clasificados con las reductoras etiquetas de Artes Plásticas y Cultura, siendo organizados - en nuestra opinión, de modo discutible, por excesivo y, paradójicamente, poco orgánico- por César Oiticica Filho y Frederico Coelho. Se trata de una antología hecha a partir de una obra multiplataforma e hipertextual que, inacabada y depositada digitalmente en la página web del instituto Itaú Cultural como "Projeto e Programa HO", mantiene, felizmente, todo su sentido e integridad en la adecuada, a pesar de dificultosa, consulta abierta online — cerca de cuatro mil documentos- o, en una versión mayor, en CD o DVD — con aproximadamente el doble-.

Es importante destacar que el criterio que rige tanto la selección, como el recorte temporal escogido no es cualitativo o representativo, sino el del carácter ancilar de estos textos críticos en relación con la actividad artística de Oiticica. Un criterio que, si bien es cierto que en diferente grado, continúa predominando en la progresiva divulgación en papel de la ingente producción escritural del artista carioca.

De este modo, ese principio preside el conjunto de los textos presentes en el catálogo de la ambiciosa exposición Museo es el mundo (Beco do Azougue Editorial, Rio de Janeiro, 2011 - Lisboa, 2012), "la mayor retrospectiva de Hélio Oiticica hecha hasta hoy", ${ }^{4}$ con curadoría compartida por César Oiticica Filho y Fernando Cocchiarale, y con un catálogo-antología organizado por el sobrino del artista, que tiene en cuenta los "textos seminales", que él afirma que "también forman parte del cuerpo de la obra". Es una selecta alargada que, reproduciendo los mismos textos de la antología anterior, apenas añade ocho textos de referente artístico e interventivo del período inmediatamente posterior al regreso del escritor de Nueva York; textos que, no obstante, son impuros y confusos como ensayos —en el doble sentido del término-, integrando elementos de lo que podríamos rotular ya como 'modo newyorkaise'.

Esta relegación a un segundo plano es, en resumen, el resultado de la supervivencia excluyente, incluso de manera apenas vestigial o inconsciente, de la idea de la obra bien hecha y del preconcepto contra lo inacabado; del todopoderoso buen gusto burgués que rechaza la cultura popular y las alternativas genéricas y textuales impuras, compuestas e híbridas; $y$, finalmente, de la intolerancia del preconcepto moralizante que excluye los márgenes vitales heterodoxos derivados de la adopción oiticiquiana, en la época, de la tríada sexo, drogas y rock'n'roll como principio vital. Un hecho que consideramos inaudito y extraño, si evaluamos la desigual fortuna crítica del período neoyorquino, apoyando nuestro juicio crítico positivo en la teorización y en las elucubraciones de Gilles Deleuze para entender el pensamiento como creación y el pensamiento artístico como modo de pensamiento específico.

A lo expuesto, de hecho, estamos tentados a acrecentar analógicamente lo que significaría, aplicada a Newyorkaises (Conglomerado), la convicción de que un libro sólo leído se puede volver sólido. De este modo, este peculiar libro oiticiquiano, voluntariamente inacabado e hipertextual, permanecería en estado líquido —osaríamos afirmar que casi

\footnotetext{
${ }^{4}$ Museu é o mundo [...] "a maior retrospectiva de Hélio Oiticica feita até hoje" (Oiticica Filho 2011: 16).

5 "textos seminais" [...] "também fazem parte do corpo da obra" (Oiticica Filho 2011: 16).
} 
gaseoso-, porque careció y carece de las necesarias lecturas cumulativas que lo puedan solidificar, con muy pocas, pero significativas, excepciones.

Entre esas lecturas pioneras e inteligentes, debemos citar la contribución de Paula Braga, que identifica "los bloques de pensamiento" y "la singularidad de su obra frente a las propuestas de algunos de sus contemporáneos". Ella, pese a que reconoce "la importancia del mito y de la [escuela de samba carioca de la] Mangueira en la obra del inventor de la Tropicálid", enfatiza que "la "síntesis" hecha por Hélio Oiticica no se deja fijar en un estereotipo cultural ya que escapa de los espacios delimitados y del tiempo cronológico, estableciéndose en un "mundo-abrigo" virtual, donde Oiticica encuentra fragmentos de las producciones de inventores de varios lugares y épocas para componer su programa más allá del arte". ${ }^{6}$

Hélio era totalmente consciente de la "frialdad y la indiferencia" y de las "medias sonrisas" de las personas — "pesimistas" y "jesuíticas", (pseudo)revolucionarios que "sobre todo hacen de las cosas y de la vida cosas feas"7, según sus propias palabras - con relación a sus experiencias desde su regreso de Nueva York, como registra en la declaración que anexa a una interesante entrevista concedida a Carlos Pereira y Heloísa de Holanda. Entrevista que, de manera significativa, se produjo en febrero de 1980, ocho días antes de su fallecimiento, reflejando la percepción distorsionada, como inacción e incluso vagancia —y también en el sentido informal de vagabundeo-, de su ingente trabajo creativo de 'regreso al futuro' y de 'pensar (y pensarse) escribiendo', durante su estancia en Nueva York.

Una prueba más de la indiferencia o desinterés frente a ese período marginal, entre Londres y Nueva York (1969-1977) — que es visto como una caída disfórica—, cuando es comparado con el período optimista, utópico y desarrollista de la década de 1950, es la evaluación del artista y estudioso uruguayo Luís Camnitzer, que concluye la elogiosa parte de su ensayo dedicada al brasileño, en su monografía sobre el conceptualismo en el arte latino-americano, con una significativa crítica:

Después de recibir una bolsa del Guggenheim, Oiticica se mudó a Nueva York (1970-1978), donde continuó trabajando en la serie de Parangolés y en otros proyectos. Inspirado por la escena disco y por las drogas, trabajó también en ambientes de slides, los Casi-Cinemas y las Cosmococas (1973), con un resultado menos satisfactorio. ${ }^{8}$

\footnotetext{
6 "os blocos de pensamento" [...] "a singularidade de sua obra frente a propostas de alguns de seus contemporâneos" [...] "a importância do mito e da Mangueira na obra do inventor da Tropicália" [...] "a "síntese" feita por Hélio Oiticica não se deixa fixar em um estereótipo cultural já que escapa dos espaços delimitados e do tempo cronológico, estabelecendo-se em um "mundo-abrigo" virtual, onde Oiticica acha fragmentos das produçóes de inventores de vários lugares e épocas para compor seu programa além-da-arte” (Braga 2007: 2).

7 "frieza e a indiferença” [...] "meios sorrisos" [...] "pessimistas" y "jesuítas" [...] "acima de tudo fazem das coisas e da vida coisas feias" (Oiticica 1980: 1).

8 "After receiving a Guggenheim Fellowship, Oiticica moved to New York (1970-1978), where he continued working on his Parangoléseries and other projects. Inspired by the disco and drug scene, he also worked on his less satisfactory slideshow environments, the Quasi-Cinemas and Cosmococas pieces (1973)" (Camnitzer 2007: 230).
} 
Nos parece que esa consideración distorsionada de la, en realidad, muy productiva estancia, está condicionada por el hecho de que Hélio practicó nuevas formas y usos artísticos inusitados y 'amoralizantes', como, por citar sólo dos ejemplos, los relacionados con la práctica del sexo y también con el tráfico y el consumo de la 'PRIMA' cocaína, nombre que explica en una carta de 1974 a una Lygia Clark que, entre 1964 y 1974, desempeña un papel muy relevante como confidente-consejera, equivalente al que Eckermann tuvo para Goethe: "Me siento como si hubiese dormido un año y me hubiese despertado con una raya de cocaína (de la PRIMA: cuando yo diga PRIMA ya sabes, es nuestra vieja amiga COCAÍNA; cosas de la nobleza incaica a la que pertenezco, como FREUD)".

Durante esos años neoyorquinos, además de presidir la conformación de su 'escritura blanca', la cocaína marca de diversas maneras su vida y obra — es una droga que sólo dejará totalmente, volviéndose incluso un 'atleta', en 1978, cuando regresa a Rio de JaneiroEn la reflexión y en la conceptualización oiticiquiana sobre la droga, Freud tiene un papel central: además del conjunto textual de experimentalismo fílmico y gráfico del 'bloquesección' Cosmococa, Oiticica escribió, en 1973, el poema 'freudhablado' "Über Coca”, a partir del artículo homónimo del psicoanalista sobre la historia y las virtudes terapéuticas de la sustancia, del cuál utiliza las referencias al héroe incaico Manco Capac — que llevó coca a los incas - para bautizar sus "Mancoquilagens". Estas máscaras de cocaína, diseñadas sobre fotografías de artistas proyectadas en diapositivas en los Block-Experiments in Cosmococa, fueron realizadas en colaboración con el cineasta Neville D'Almeida. De ellas puede servir como un ejemplo paradigmático la 'mancoquilagem' número 4, Nocagions, dedicada a Haroldo y Augusto de Campos, en la que el blanco de la coca se superpone al blanco de la portada del libro Notations, del músico y poeta experimental John Cage, con el valor de cage (jaula), en un homenaje-asunción reinterpretado del Blanco sobre blanco de Malevitch.

Ese 'blanco esencial' ya no es el de significado suprematista ni el de interpretación constructivista, porque su significado, en una "lectura sincrónico-retrospectiva" aplicando aquí el concepto creado por Haroldo de Campos-, actualizado por el filtro de la lectura de la reedición de 1973 del Poetamenos de Augusto de Campos, se establece en relación con lo corporal, con el arrebatamiento y con lo sublime. De hecho, en una cinta dedicada por Hélio al concretista Augusto en 1974, podemos oír la siguiente interpretación entrecortada del blanco y del poema de este último "dias dias dias", bajo la sombra del texto poético "AMORTEMOR", también del mayor de los hermanos Campos:

Creo que el blanco... bueno una cosa absurda que descubrí cuando pasa eso: "a” y después "mor" es "amor", pero es muerte, pero ahí tú nunca... uno se queda así inmediatamente completando "mor", con muerte pero la sílaba "T-E” en realidad

\footnotetext{
9 "Sinto-me como se tivesse dormido um ano e acordado com uma cafungada de pó (da PRIMA: quando eu disser PRIMA já sabe, é nossa velha amiga COCAÍNA; coisas de nobreza incaica à qual pertenço, como FREUD)" (Clark y Oiticica 1998: 226).
}

10 "leitura sincrônico-retrospectiva" (Campos 1976: 13). 
el blanco la está cubriendo es a mi entender pasan muchas veces cosas así de que la cocaína aparezca y desaparezca en ese... es decir es todo como si fuese una especie de ejercicio así de ambivalencia de la persona... yo qué sé además el blanco de esa cosa tiene algo así de nieve un poco de nieve de nieve también es ya cocaína "snow" esa cosa [...] no es libro son espacios fílmicos, Bloques-espacios-fílmicos. ${ }^{11}$

Por lo tanto, lo que explica esa escritura blanca no es sólo la cocaína, sino especialmente una búsqueda mentalmente canibalizadora de influencias - y afluyentes confluencias- de diferente naturaleza. Sin embargo, es el preconcepto ético-estético burgués el que explica —y, de hecho, sustenta — la incomprensión y el rechazo del orgullo de Oiticica con relación a su 'otium activo'. Un, en sus propias palabras, 'dolce far niente creativo' que, en consonancia con el 'retiro mental' de Artaud y el intermezzo ajedrecístico de Duchamp, fundamenta citando una frase ad hoc —incluso ad personam - de la obra Everybody's Autobiography, de su admirada Gertrude Stein, en consonancia con la atenuación de la interpretación autobiográfica de la Rróse Sélavy duchampiana: "lleva mucho tiempo convertirse en un genio. Es necesario sentarse mucho tiempo y quedarse sin hacer nada, realmente sin hacer nada" 12 .

En fin, antes de continuar con la descripción y el análisis ponderado de la escritura newyorkaise, vamos a intentar a través de algunos exempla y de unos pocos consideranda, re(a)sumir la trayectoria artística de Oiticica en una apreciación general, dividida en siete momentos que, creemos, fundamentan las ideas admitidas consensualmente, en el sentido en que Ana de Hollanda afirmó que la obra del artista carioca "representa, para las artes visuales, un territorio de mutación y transición entre lo moderno y lo contemporáneo, donde arte y vida forman parte del mismo universo". ${ }^{13}$

Por una parte, en un pobre resumen evaluativo, podríamos afirmar que Oiticica cuestionó la distancia existente entre la pintura y la escultura, pasó de la comunicación mental de la abstracción geométrica (neo)concreta a una percepción senso-corporal, evolucionando desde una representación pictórica, intelectiva y bidimensional, hacia los relieves pintados, las picto-esculturas suspensas y, en un cambio sensorial, hacia actuaciones performáticoexperienciales y, de modo pionero, también hacia instalaciones de arte ambiental.

\footnotetext{
11 "eu acho que o branco... bom uma coisa louca que eu descobri quando tem aquele negócio: "a" e depois "mor" é "amor", mas é "morte", mas aí você nunca... a gente fica assim imediatamente completando "mor", com morte mas a sílaba "T-E" na realidade o branco tá cobrindo ela é a meu ver a gente tem muita dessa coisa assim do pó aparecer e desaparecer nesse... quer dizer é tudo como se fosse assim uma espécie de exercício assim da ambivalência da pessoa... sei lá aliás o branco dessa coisa tem uma coisa assim de neve um pouco de neve de neve também já é cocaína "snow" essa coisa assim [...] não é livro são assim espaços filmicos, Blocos-espaços-filmicos" (Cit. en Aguilar 2006: 23).

12 "it takes a lot of time to be a genius, you have to sit around so much [,] doing nothing, really doing nothing" (Oiticica 1974b).

13 "representa, para as artes visuais, um território de mutação e transiçấo entre o moderno e o contemporâneo, onde arte e vida fazem parte do mesmo universo" (Hollanda 2011: 7).
} 
Por otra parte, para utilizar pocas palabras, en una visión panorámica y aproximativa, podemos enumerar, de manera lineal, siete etapas esenciales en las experimentaciones, continuas y 'bulímicas', de su trayectoria. En primer lugar, de la racionalidad pictural concreta de los "Metaesquemas" - instaurada en el marco del concretismo carioca del "Grupo Frente", en el que se había integrado en 1954, hasta su disolución cuatro años después- transita hasta la mayor laxitud y la menor rigidez de un modo gullarianamente neoconcreto.

En un segundo momento, a partir de 1959, en el marco de una conceptualización del color-tiempo, experimenta con los "Monocromáticos" y, a continuación, con las pinturas de dos caras "Bilaterais" que rebasan el 'plano del cuadro' y salen fuera del rectángulo convencional, y con los "Relevos espaciais", relieves que emergen de la pared y que, en una evolución lógica y natural, con su problematización de las relaciones entre la estructura y el color, dan origen a los "Núcleos" y a la participación del espectador en la obra.

Después del primer "Penetrável" de 1960, se declara el fin del cuadro convencional y, poco a poco, se afirma una pintura penetrable y habitable para el espectador y perceptible corporalmente, materializada, a partir de 1963, en los "Bólides", apreciables de modo sintéticamente suprasensorial —claro que con excepción del gusto, o sea, únicamente a través de sensaciones visuales, táctiles, olfativas y/o auditivas-.

En un cuarto momento, al año siguiente, concluyendo su camino desde lo internacional hacia lo nacional, en la experiencia, mítica y mistificada, del samba y del barrio marginal del Morro da Mangueira — que, de hecho, adopta como emblema la máxima "Sea marginal, sea un héroe"14 (1968) y la acción artística inspirada por el asesinato del bandido Cara de Cavalo_-, surgen los primeros "Parangolés". Parangolés, que, como es sabido, son una especie de capas vestidas por los marginales de la Mangueira al entrar en el Museu de Arte Moderna de Rio, en 1965, y que integran el cuerpo ambientalmente en la arquitectura de la obra y, en particular, en el propio color.

Tres años más tarde, en 1966, Hélio produce una síntesis a través de la famosa instalación "Tropicália", presentada en 1967. En ella añade a las dimensiones estructural - americana e internacional - y participativo-sensorial del espectador, a las que había concedido preferencia hasta entonces, la de la dimensión anarco-política y el principio etnológico-marginal, presentes en el, y por él brasílicamente denominado, constructivismo favelado.

En 1969, añade la dimensión de lo 'inoperante’, basada en la conceptualización del 'crelazer' — neologismo que podríamos traducir como 'creocio'-, que será sintetizado en ese mismo año en la célebre, relevante y heterogénea instalación londinense de la Whitechapel Gallery.

Por último, en la última década de su vida, Hélio se convierte básicamente en un escritor obsesivo, habitando y practicando los márgenes de lo social hasta 1978, en su voluntario exilio neoyorquino, entre los tabiques transparentes, con paredes maleables, de sus "Ninhos", nidos o estructuras que creó en los dos pisos en los que vivió. Al mismo tiempo,

14 "Seja marginal, seja herói”. 
concibe obras públicas ambientalistas —alguna materializada cuando regresa a Rio- y experimenta con el cine y la fotografía.

Nueva York y Rio son dos ciudades que Oiticica simbólicamente une en los márgenes, por medio de un pedazo 'mágico' de asfalto de la Avenida Presidente Vargas que tiene la forma de la isla de Manhattan, un objeto que Hélio recogió en una deambulación en 1979 y que provoca el 'delirio concreto' de su poema visualmente ideogramático "Agripina é Roma-Manhattan" - y, posteriormente, el casi-film homónimo- y la instalación del mismo en su cuarto de baño. Una deambulación que, en una entrevista concedida a Ivan Cardoso, explícitamente relaciona con la canción de Caetano Veloso "Enquanto seu lobo não vem", de 1968, porque evoca el placer hedonista y el peligro del delirio del laberinto y de la liberación dionisíaca (cit. en Lucchetti 1990: 68-70).

A pesar de preferir un error a una simplificación, como Spinoza, estos siete puntos pretenden respetar tanto la compleja realidad del recorrido artístico factual de Oiticica, como el condicionante, pero luminoso, testimonio verbal de discernimiento que él produjo ad hoc. No es concidencia que, ya en 1961, en una entrevista al periódico Jornal do Brasil, declarase:

Me parece importantísimo que los artistas ofrezcan su propio testimonio sobre su experiencia. La tendencia del artista es la de ser cada vez más consciente de lo que hace. Es más fácil penetrar el pensamiento del artista cuando deja un testimonio verbal de su proceso creador. Me siento obligado a hacer anotaciones sobre todos los aspectos esenciales de mi trabajo. ${ }^{15}$

En fin, creemos que es necesario, no obstante, pedir disculpas por esta clasificación taxonómica, típica de una posición reduccionista, que, en todo caso, difícilmente podríamos pretender evitar de todo, porque estamos convencidos tanto de la complejidad como de la sinuosa y controvertida coherencia del recorrido del autor. Recorrido que, entre el hábitat, la habitación y la habituación, estructura su doble trayectoria experiencial-interventiva y plástico-escritural, desde la representación del espacio elaborada por el artista y observada por el espectador, hasta la experiencia vivida por este y experimentada y activamente creada por aquel.

Por poner sólo un primer ejemplo de esa coherencia espiralada, podemos pensar en las manifestaciones autorales de distancia con relación al geometrismo abstractizante, pero dinamizado por la percepción del color — pese a la fría coloración racionalista utilizada- y de los experimentos con el plano en los "Metaesquemas", en algunos casos acompañada de un cierto rechazo displicente de esos guaches sobre cartón realizados entre 1957 y 1958. Rechazo y distancia basadas en su progresivo, pero persistente, abandono de la pintura y

15 "Acho importantíssimo que os artistas deem seu próprio testemunho sobre sua experiência. A tendência do artista é ser cada vez mais consciente do que faz. É mais fácil penetrar o pensamento do artista quando ele deixa um testemunho verbal de seu processo criador. Sinto-me sempre impelido a fazer anotaçóes sobre todos os pontos essenciais do meu trabalho" (Oiticica 2009: 25). 
en su práctica de un nuevo orden plástico que, invadiendo el espacio, acaba relacionando dialécticamente los saberes experienciales, sensitivos y perceptivos con un reconocimiento reflexivo de una función alternativa y libertaria, para que el arte actúe de manera efectiva en la sociedad.

Oiticica, en una especie de palinodia, resignificando el pasado y regresando al futuro, en el verso de su paradigmático "Metaesquema Sêco 27" de 1957, once años más tarde, escribe la siguiente nota manuscrita — destacada de modo recurrente en diversos análisis de esa obra, como los de Paula Braga, Sérgio B. Martins, Adele Nelson o Roberto Conduru-:

Considero este trabajo importante hoy, y para mí, en aquella época, fue desconcertante por su sentido de 'disolución estructural', más allá del espacio meramente pictórico — es que yo aún quería la renovación de este espacio, pero aún no estaba preparado para el salto o la transformación- pero hoy veo que este trabajo estaba a la vanguardia, en el conflicto entre espacio pictórico y extraespacio y anuncia directamente la aparición de los Bilaterales, Núcleos y Penetrables. ${ }^{16}$

Lo que en ese momento comprende el autor, por lo tanto, es la existencia de una búsqueda de lo tridimensional en el guache que antes había plasmado de manera no totalmente consciente.

Intentaremos explicar mejor esta idea, en la medida de lo posible, a través de un segundo ejemplo relacionado con su Poética secreta de 1964. Una obra que Hélio, pese a que no se consideraba poeta, afirma iniciar en esta fecha - hasta 1966 - como consecuencia de una necesidad de expresión verbal inmediata, opuesta a la manera mediata - y mediatizada - con la que, en ese período, elabora su obra plástica. Esa notable —y poco conocida - obra poética, básicamente constituida por once poemas (para)concretos y tres haikais es creada a partir de la consideración de la memoria como dimensión temporal, como 'sedimentación de recuerdos' capaz de transformar vivencias, intentando capturar el sentido del flujo del tiempo por medio de sensaciones táctiles.

$\mathrm{Si}$, tal como propuso Anita Ayres (2015), confrontamos el poema "O cheiro" — "El olor" - con uno de los metaesquemas de 1958, el primer poema de la colectánea sobre el olor pone de manifiesto, de manera natural, cómo su escritura se asemeja a la del referido metaesquema. La semejanza consiste en la correspondencia, grosso modo, entre la preocupación-disposición espacial de los rectángulos del guache y la paralela disposiciónpreocupación espacializada de los versos, a pesar de los presupuestos abstracto-geométricos que presiden el primero y los distantes sinestésico-sensoriales tematizados en el segundo.

\footnotetext{
16 "Considero este trabalho importante hoje, e para mim, na época, foi desconcertante pelo sentido de 'diluição estrutural', além do espaço meramente pictórico —é que eu ainda queria a renovaçáo deste espaço, mas ainda nấo estava preparado para o salto, ou a transformação- mas hoje vejo que este trabalho estava bem à frente, no conflito entre espaço pictórico e extra-espaço, e prenuncia diretamente o aparecimento dos Bilaterais, Núcleos e Penetráveis" (Oiticica 1968b).
} 
No obstante, lo que aquí nos interesa, con relación a estos dos ejemplos de la coherencia zigzagueante del recorrido de Oiticica, es la naturalidad con la que - tanto el propio autor, como nosotros, espectadores-partícipes - podemos replantear y relacionar las obras desde y en el futuro del pasado, superando el abismo de concepciones y tiempos, en una especie de espiralado 'pantiempo eliotiano' o nietzschiano 'eterno retorno' afluentes e influyentes en la particular y sorprendente idea del "crelazer" de Oiticica. En este sentido, en un manuscrito de 1968, podemos leer sobre su pensamiento del "neotiempo":

Todo está relacionado con el pasado y no lo está, está claro, incluso el presente y el futuro; pero y si le dijese que no siento esa relación entre pasado-presente-futuro? Entonces todo se borra y desaparece, porque cuando se vive el crelazer, eso no existe; el gran descubrimiento del mundo actual sería vivir en absoluto, sin la vieja relación de tiempo cronológico, que es represiva y cruel. ${ }^{17}$

En fin, por eso, en una perspectiva holística, el conjunto de la obra artística y escritural que presentamos sumariamente y el conglomerado escritural 'babilónico' de Oiticica surgen, si nos permiten la analogía inspirada por el apellido arbóreo del autor, como el 'jardín imperfecto' de Montaigne, un jardín acrónico — por ser repetidamente anacrónico-y nietzschianamente 'inactual', en permanente proceso de redefinición, o sea, un jardín nunca concluido y que cada generación o cada grupo de lectores cultivará con sus propios instrumentos y modelará de acuerdo con sus propios códigos.

De este modo, con un discurso alusivo que se aproxima a veces peligrosamente al abismo y como una respuesta a la cuestión de la obsolescencia de ciertas convenciones de la modernidad, Newyorkaises está formado, en gran parte — y a menudo, incluso en el registro de las proyecciones, mentales y heteróclitas, de obras artístico-interventivas a realizar-, por una escritura 'ego-socio-psico-histórica', polimórfica, imprevisible, inestable, cuando, en realidad, sería de esperar la precisión y los contornos, más o menos, fijos, que presiden su escritura sobre arte y su reescritura del arte hasta la década de 1970, que explica y en los que se explica con precisión 'metronómica'.

Aún diríamos más, las prácticas artísticas posteriores a la década de 80, incluyendo las "contraartísticas" del "arte de guerrilla" 18 — de acuerdo con la propuesta de Frederico Morais - y, dentro de ella, el conceptualismo — sobre el cuál el propio artista habla y profetiza en su discurso crítico- acabaron convirtiendo también esa parte de su obra en la de un pionero o, por así decirlo, en la de un borgesiano 'plagiario', anticipadamente a(na) crónico.

17 “Tudo está relacionado com o passado e não está, é claro, inclusive o presente e o futuro; mas, e se lhe disser que não sinto essa relação entre passado-presente-futuro? Então tudo se borra e desaparece, porque quando se vive o crelazer, isso não existe; a grande descoberta do mundo atual seria o viver em absoluto, sem a relaçáo velha de tempo cronológico, que é repressiva e cruel” (Oiticica 1968a: 3).

${ }^{18}$ Las "contra-artísticas" del "arte de guerrilha" (Morais 1976: s./p.). 
Para realizar un análisis más concreto y apreciar en su contexto esta obra construida por el singular escritor - y plural artista - durante su exilio voluntario en los años 70 en Manhattan —incorporando también fragmentos diarísticos de la década de 60-, nos centraremos, en este discurso (necesariamente) heteróclito, en la "Carta a Waly" —una transcripción dactilografiada que es fiel a la carta al poeta Waly Salomão, manuscrita en un cuaderno para ser publicada, y que, de hecho, fue editada en la revista Pólem en 1974_, en el manuscrito "Poema MILLERIMBAUFICADO”, utilizando sólo referencias puntuales al bloque-sección "Bodywise" y a las anotaciones de la "Parangolé-Síntese", así como en otros materiales 'hipertextuales', escritos en 1972 y 1973, en Nueva York.

Oiticica consideraba Newyorkaises un 'libro entre comillas' por su carácter singular $-\mathrm{y}$, a fin de cuentas, inacabadode conciencia, de intuiciones, de asociaciones y de recuerdos manuscritos en pentimento - a veces dactilografiados horacianamente-, y por su exigencia de una experiencia de lectura simultánea. En cuanto tal, el libro podría ser definido también tanto dentro de los parámetros de un sketchbook artístico y de un blanchotinano livre à venir literario, o incluso, a la manera de un inestable perpetuum mobile, en continuo crecimiento, y de un inaprensible work in progress, en una aprehensión por extenso de lo acuñado por René Wellek y Austin Warren en su proverbial y (re)conocida teorización literaria de la obra 'clásica'.

En este 'libro-conglomerado', el lector es invitado a una experiencia extraña, contraria al horizonte de expectativas por él instituido, en una vuelta de tuerca inventiva más, en la que Oiticica, con un fuerte individualismo y una poética inusitada de la exageración, del exceso lúcido, anotando el "fulgor primero de las ideas" (Cit. en Arijón 2013: 9), hipertrofia y amplía los caminos de la literatura al cruzarla con otros discursos y referencias culturales, como el plástico, el cinematográfico, el musical o el crítico, dando testimonio y contaminando la sensibilidad de una época en un modelo total y omnívoro de escritura.

Así se crea una discursividad que, entre la inventio y la apropiación — distante del irónico 'crimen [de plagio] perfecto' del cronista Rubem Braga-, crea textos que aluden y/o citan fragmentariamente otras obras literarias y artísticas, en sentido amplio. O sea, se trata de textos inacabados y sin contexto que se presentan, como sucede, por ejemplo, en el caso del texto "Jeanne Rimbaud d'Arc (Apropriaçáo de Uma temporada no inferno)" de 1971, como alegorías de alegorías de un pensar espontáneo, de un pensar también con el cuerpo y que, en Newyorkaises, crean una red compleja de relaciones, con la ayuda de las cuales son interpretados, porque acentúan y aumentan ciertos significados: en especial, aquellos que, de la afinidad a la coincidencia, refuerzan elementos ya asumidos por Oticica como operativos y válidos para su pensamiento y para su escritura in progress.

Es igualmente interesante comentar también brevemente algunas de las notas preparatorias de Newyorkaises redactadas en 1973, en lo que respecta a los posibles títulos pensados por el artista y a la razón de la elección final del título en francés. La complejidad del Conglomerado radica, en parte, en el uso indistinto del portugués y del inglés, de modo menos sólido del francés y, ocasionalmente, de otras lenguas, pero también se debe al uso de 
la mot-valise y de los juegos semánticos de polisemia y de enriquecimiento por acumulación de significado o ambigüedad fónica y evocación paronomástica.

En este sentido debe ser entendido el (neo)adjetivo compuesto singultâneo, creado por el artista y que aplicamos a la 'escritura' oiticiquiana que estamos analizando. Ese adjetivo es explicado en una carta a Haroldo de Campos de 1974, en la que Oiticica, comentando el poema-homenaje compuesto por Haroldo "Parango(h)elium" y las singularidades simultáneas compartidas por los hermanos Campos y él mismo, dice "YESSYING SIMULTÁNEO: VOILÀ! SINGULTÂNEO (q término full of pregnancies ¿̇no?)", ${ }^{19}$ definiéndolo como una afirmación simultánea — siendo esta la singularidad de cualquier época-, como innovación y convivencia atemporal de singularidades no hierarquizadas y como la extensión de la idea de Alfred Jarry de que las palabras son poliedros de ideas.

Esa multiplicación acumulativa de significados de (neo)significantes lexicales complica más esa delimitación de un objeto artístico — casi estamos tentados a afirmar que se trata de un OVNI, de un objeto artístico-escritural no identificado- impreciso, vasto y heteróclito como el que nos ocupa, porque, como vemos, la teorización y conceptualización oiticiquiana es el resultado tanto de sus experiencias y constructos teorético-relacionales, como fruto de aquellos que otros - y en otras realidades - nos prestan. Pero volvamos a los hermanos Campos y ejemplifiquemos la apropiación de ese préstamo: Haroldo bautiza ad hoc los registros sonoros de las conversaciones de Hélio como heliotapes que, además del claro juego significativo en inglés, Raúl Antelo asoció al lugar y a los indios tapes de Rio Grande do Sul, pues, para Haroldo, Oiticica es como el 'héroe con carácter' de Mário de Andrade, el cantante nordestino Chico Antônio, que hace lo que el escritor no osa hacer (Cit. en Aguilar 2006: 70).

Forman también parte de este ámbito las variaciones de NEWYORKAISES, en francés, 'las habitantes o cosas de Nueva York', un término que permite, además, la confusión paronomástica con el inglés NEWYORCASES y, en consecuencia, multiplicar ambiguamente los significados posibles, como 'caso', 'causa', 'asunto', 'caja', 'acontecimiento', 'funda, 'situación', 'problema' o 'proceso' neoyorquino.

Después de registrar otras posibilidades lingüísticamente híbridas del francés, inglés o portugués para el título, observamos también, inter alia, la cita en francés de un verso del poema de Rimbaud " Matinée d'ivresse ", que se debería situar en la publicación en página blanca inicial, y, para citar sólo las primeras dos líneas de cada canción, la selección de Torquato [Neto] de fragmentos en inglés de las canciones "Let it Bleed", "Live with Me", "Sister Morphine", de los Rollings Stones, entre los que menciona a Mick Jagger y Keith Richards.

Ya en el poema 'MILLERIMBAUFICADO' "S'il était bien éveillé », el principio enciclopédico que preside la elaboración de la escritura branca y singultânea, hace que aparezca uno de sus constantes referentes, el 'inventor' Rimbaud. Aparición provocada por

19 "YESSYING SIMULTÂNEO: VOILÀ! SINGULTÂNEO (q termo full of pregnancies não?)" (Cit. en Aguilar 2006: 58). 
el embelesamiento que le produce la obra-vida del poeta francés —el título es un verso del poema "L'impossible " (en el slang neoyorquino, el coke-dream es el sueño 'imposible' que sólo la cocaína permite) - y la fascinación provocada por el ensayo The Time of Assassins: A Study of Rimbaud (1956) de Henry Miller. Autor homenajeado en ese texto lingüísticamente anglo-franco-portugués - y castellano-, amalgamando un significado conglomerado del "SUEÑO DE COCAÍNA", la "pereza-paresse", el "esprit" y la "sagesse", la "neige-sol" y el "SOL-SUELO"20 y también la proyección sinuosamente oblicua de la escritura del 'yo', por medio del diseño 'infantilizado' de un feliz sol que se convierte, gracias al sempiterno recurso retórico de la interpretatio nominis, en emblema del propio nombre solar Hélio anagramáticamente presente in absentia también en el francés soleil-.

En el contexto habitual de las aproximaciones 'trascendentes' al pensamiento artístico de Oiticica, consideramos que es necesario también realizar un estudio de los recursos utilizados por el escritor-artista en su arte ingenioso, lúdicamente representativo de las referencias 'biografiables' del 'yo', vividamente escritas. Entre esos recursos, salvando las debidas distancias, tal como en la arte engenhosa de Camóes — por dar sólo un ejemplo, podemos recordar el fascinante soneto "Alegres campos, verdes arvoredos" y la reduplicación de la presencia del sujeto lírico en la descripción anamórfica del blasón de su linaje en el inicial locus amoenus (que se vuelve terribilis) — , sobresalen las referidas interpretación nominal y anamorfosis.

En este sentido, en el principio de la "Carta a Waly [Salomão]", de 1974, "que es material para publicar", ${ }^{21}$ hace referencia, significativamente, entre otros, de su día a día, al fait-divers del 'call me Hellium' —llámame Hellium—, una frase de la última entrevista de Jimmy Hendrix, estableciendo un alusivo paralelismo entre el gas helium y 'hélio', entre Hendrix y él mismo — como cuando Alfonso X, el Sabio, pensó que estaba predestinado a elaborar su excelente tratado en prosa sobre el número siete, El setenario, por tener su nombre, Alfonso, siete letras y comenzar con alfa y acabar con omega-.

La coincidencia de esa 'predestinación' con relación a Hendrix, cuya música, como él mismo nos dice, oye cuando escribe, es la base de su quinta cosmococa (para)fílmica "Hendrix-War", realizada en el año 1973, en coautoría con Neville. Inmediatamente después de esa explicación sobre la inspiración del músico de Seattle, menciona, en la carta, a los hermanos Campos y la cocaína, retoma palabras de canciones de Hendrix, crea un ambiente sudorosamente carnalizante y sexualizado, cita versos de canciones de los Rolling Stones, refiere el convite para la mítica exposición de 1974 en el MoMA "A Valentine for Marcel Duchamp” e, indirectamente, evoca la música y la poesía anagramática de John Cage, reasumiendo todos los referidos 'inventores' y añadiendo la "SNOW-YOKOPIECE" de Yoko Ono, también presente en la cosmococa CC2 "Onobject" de 1973. Es decir, este comienzo en el que asocia, entre otros, los nombres de diferentes artistas que

20 "COKE DREAM" [...] "preguiça-paresse" [...] "esprit" [...] "sagesse" [...] “neige-sol” [...] "SOL-SOLO" (Oiticica 1973).

21 "que é material para publicar" (Oiticica 1974a: 1). 
comenzaban a proponer diversas formas de participación del público, anuncia el vértigo de la asociación y proyección cultural y biográfica que construye, intelectual y poéticamente, la carta genéticamente suprasensorial — pese a que la relevancia de esa posible proyección sea, a veces, anecdótica- En este sentido de lo (neo)participativo, el profesor argentino Mario Cámara, en su ensayo Cuerpos paganos - Usos y efectos en la cultura brasileña (1960-1980), ha señalado el interés de Oiticica con respecto a esos artistas precursores, destacando ciertas afinidades identificadas por el artista brasileño, como las existentes entre Cage y Hendrix:

Tal como Oiticica lo plantea, Cage y Hendrix poseen al menos un punto en común: producir un arte abierto al acontecimiento, dado por la participación no mediada del público. En el caso de Cage, el público no necesitaba saber música, con que alguien tosiera en la sala la música ya se estaría produciendo; en el caso de Hendrix, nadie allí necesitaba saber bailar, bastaba con sumarse a la música que emanaba desde el escenario. Los conciertos de Cage y Hendrix eran situaciones sometidas al azar - la tos de un espectador, el incendio no premeditado de la guitarra- $\mathrm{y}$, en virtud de ello, a la producción de acontecimientos (Cámara 2011: 133).

Por otra parte, el ejercicio de pensar y escribir esa amalgama continua, con la repetición modulada del sol, aparece en un segundo momento en la "Carta a Waly", representado como un sol vitalmente rojo, con un centro irradiador de 'polvo' - de cocaína-, acompañado por referencias a Augusto de Campos o a Artaud (Oiticica 1974: 7) $-\mathrm{y}$, de nuevo en una (re) interpretatio nominorum de Hélio, al emperador romano, cruel y disoluto, Heliogábalo, al que el francés había dedicado su ensayo Héliogabale ou l'Anarchiste couronné (1934) - . La carta acaba con unos anexos, que presentan instrucciones de edición e indicaciones complementarias de disposición y de ilustración, básicamente fotográfica y plástica, y, además de lo publicado, se completa in progress en una delirante adenda manuscrita.

Así, aprovechando las referencias vitales y la discursividad de autores y autoras que son sus frères (o soeurs) d'ombre — tal vez sería preferible hablar aquí de lúdico y lúcido soleil—, utiliza la cita oblicua, el proceso que Antoine Compagnon denomina 'reescritura', es decir, un ejercicio basado en dos operaciones, una de extirpación y otra de injerto. Este es un procedimiento que caracteriza, a grandes rasgos, las Newyorkaises en el magma del conjunto experimental del autor, en la construcción de un admirable collage, que funde la propia discursividad y ciertos fragmentos de la discursividad de otros, fragmentada en un proceso típicamente contemporáneo.

Resulta notable, por lo tanto, la manera en la que la carta desarrolla diversos elementos ambivalentemente significativos de la potencia (in)activa e (in)consciente del "polvo" de la cocaína, del "optimismo SOÑADO-INTOXICADO", ${ }^{22}$ de la ausencia y de la pausa creativa de la 'escritura blanca', recurrente en los diferentes 'bloques' de este

22 "pó” [...] "otimismo SONHADO-INTOXICADO” (Oiticica 1974a: 4). 
'libro entre comillas', como el abandono rimbaudiano de la poesía, el nietzschiano "sol del mediodía" 23 —el del cayado coronado con un sol dorado (del conocimiento) ofrecido por sus discípulos a Zaratustra-; el rimbaudiano "SOL SUELO", el "SUELO DE NIEVE ETERNA"; el "SOL-MALEVICH" o el manto del "ÁNGEL HAGOROMO japonés"24. Esta última imagen hace referencia al Hagoromo de Zeami, obra clásica del teatro Noh japonés traducida y 'transcreada' por Haroldo de Campos, quién, de manera notoriamente significativa, afirma en el texto "Parafernália para Hélio Oiticica": "donde se lee hagoromo, léase parangolê". ${ }^{25}$

Se trata, por lo tanto, de elementos imprescindibles para la materialización de los estados-reflexiones creados por esos autores 'inventivos', creadores de la válida 'invención' poundiana - y de transmisión y teorización concretista en Brasil— de la que anteriormente hablamos como única opción posible de 'crelazer' para Hélio.

Centrándonos ahora, para empezar a concluir, en el caso de Haroldo, constatamos como Oiticica resignifica y actualiza el sensorial parangolé en parámetros de revelación —en parámetros de un delirio trascendente paralelo al del "Manto da Apresentação" del alienado artista brut Arthur Bispo do Rosário-, de unión entre el cielo y la tierra que funde "LUZ en el CIELO DEL CIELO" como el "blanco sobre el blanco"26, haciendo vibrar en optimismo a Nietzsche y Rimbaud. La mención del Hagoromo de Zeami - O charme sutil — publicado por Haroldo en 1994 - y de la Tennin — la 'doncella celeste' y/o ángel' budista - que porta el hagoromo (manto de plumas), está relacionada con el hecho de que, en esa época, Haroldo dedicó a Hélio, en la obra, la traducción del "Canto final del coro" (kiri), haciendo una comparación entre el hagoromo de la ninfa celeste y los parangolés. El propio Haroldo de Campos explica la relación:

Además de las cartas que nos enviamos en aquella época, las impresiones de Hélio, instigado por ese paralelismo, están vivamente registradas en su diario neoyorquino (1973) [se refiere a los textos "PARANGOLÉ SINTESE" (1972) y a las anotaciones para el bloque "BODYWISE" (1973)]. Hélio incluso imaginó la posibilidad de un parangoplay ("parangopieza")... En 1979, de hecho, la fusión hagoromo/parangolé me inspiró un poema ("Parafernalia para Hélio Oiticica"), incluído en el guión de la película H.O., de Ivan Cardoso, homenaje a nuestro inolvidable amigo [...] De esa fusión, nació la idea del Parangoromo, proyecto de escenificación de mi transcreación de Hagoromo, con la participación de Caetano Veloso y dirección de Julio Bressane, substituyéndose el "manto de plumas" por uno de los "parangolés"

\footnotetext{
23 "SOL DO MEIO-DIA" (Oiticica 1974a: 3).

24 “SOL SOLO" [...] "CHÃO DE NEVE ETERNA" (Oiticica 1974a: 3) / "SOL-MALEVITCH” [...] "ANJO HAGOROMO japonês” (Oiticica 1974a: 4).

25 "onde se lê hagoromo, leia-se parangolê" (Campos 1976: 3).

26 "LUZ no CÉU DO CÉU” [...] "BRANCO SOBRE O BRANCO” (Oiticica 1974a: 4).
} 
de Hélio. El proyecto aún no tiene las condiciones de ser llevado a la práctica. Está, por ahora, al cuidado de la actriz y teatróloga Alicek, especialista en Noh. ${ }^{27}$

Para eso, en este vademécum de Héliocubraçôes neoyorquinas — sirviéndonos de la feliz invención del poeta y designer André Vallias—, la influencia haroldiana instituye un magma de significaciones circunscritas a los ámbitos de la innegable obsolescencia de los valores pasados y de la indispensabilidad de nuevas búsquedas y de los consecuentes fracasos. No obstante, no se debe olvidar que el final de esos principios estéticos derrumbados no es sinónimo de la ruptura con el pasado de los 'inventores' ni, en especial, con el pasado reciente de la obra previa de Oiticica.

Permítannos, para concluir esta necesariamente heteróclita — y adecuadamente (des) organizada - exposición, intentar deshacer otro equívoco de los manuales — aquellos de los cuales Roman Jakobson dijo que debemos desconfiar- El preconcepto de la durabilidad del distanciamiento entre el neoconcretismo y el concretismo, entre la subjetividad corporal carioca y la frialdad intelectual paulista, por más que su relación fuese más recíprocamente connivente que transitivamente cómplice, no es correcto, como demostró Gonzalo Aguilar: en esa época, los ya 'exconcretos' Décio Pignatari y los hermanos Campos y, en especial, el Haroldo posterior a 1964 y a las Galáxias, auténtico maître-à-penser, tuvieron una gran influencia intelectual sobre Hélio Oiticica —a distancia e in person-, en esos años contraculturales en Nueva York. Este hecho se debe, también, a que los concretos se aproximaron (mucho) de lo corporal, a través de los tropicalistas bahianos y a que Hélio mantuvo siempre su programa constructivo. Puede parecer extraña esta consideración, pero conocemos la tarea homérica de inversión de los prejuicios críticos, de las idées reçues $\mathrm{y}$, en especial, de la lucha contra los 'ídolos' de las generalizaciones y de las convenciones — lucha esta última que, recordémoslo, ya Francis Bacon consideraba enormemente complicada-.

En este sentido, por más que se repita, esto no debería ser asumido como una verdad. Además de lo referido antes, bastaría llamar la atención sobre el claro emblema que representan las fotos de la portada del primer y único número de 1974 de la revista, contracultural y experimental, Navilouca - Almanaque dos Aqua-Loucos. Una revista planificada durante dos años y dirigida por Waly Salomão y Torquato Neto — quien se suicida en 1972 - y cuyo título — y no por casualidad — deriva de la 'nave de los locos', de la Salutifera Navis medieval, a través de las referencias a ella hechas por Foucault en sus conferencias sobre la locura en Rio en 1973. Esas fotos son testimonio, sin ambigüedad,

\footnotetext{
27 "Além das cartas que trocámos à época, as impressóes de Hélio, instigadas por esse paralelo, estão vivamente registradas em seu diário nova-iorquino (1973). Hélio chegou a imaginar a possibilidade de um parangoplay ("parangopeça")... Em 1979, aliás, a fusão hagoromo/parangolé inspirou-me um poema ("Parafernália para Hélio Oiticica"), incluído no roteiro do filme H.O., de Ivan Cardoso, homenagem ao nosso inesquecível amigo [...] Dessa fusão, nasceu a idéia do Parangoromo, projeto de encenação desta minha transcriação de Hagoromo, com a participação de Caetano Veloso e direção de Julio Bressane, subtituindo-se o "manto de plumas" por um dos "parangolés" de Hélio. O projeto ainda não encontrou condiçōes de ser levado à prática. Está, no momento, aos cuidados da atriz e teatróloga Alicek, especialista em Nô” (Campos 2006: 17).
} 
de la sobreposición y confluencia de 'viejos' - Lygia Clark, los hermanos Campos o Pignatari-y 'nuevos' o 'novísimos' - Hélio Oiticica, Rogério Duarte, Caetano Veloso, Torquato Neto, Duda Machado, los hermanos Salomão, Waly y Jorge, Stephen Berg, Luiz Otávio Pimentel, Óscar Ramos, Ivan Cardoso, Chacal, Luciano Figueiredo-; de escritores, teóricos, artistas e 'interventivos'; de tendencias — concretos y neoconcretos, tropicalistas, ambientales y otras 'tribus marginales' — o de pretensas distinciones localistas — bahianos, cariocas o paulistas-.

Oiticica está de acuerdo con la 'invención' de Duchamp — de hecho, mencionado, significativamente, en la carta a Waly y en su adenda - de que una obra de arte no es la materialización de una idea inmaterial y de que la idea en arte es sobretodo una anticipación de sus efectos, de los efectos generados por su materialidad, pero discrepa de la convicción duchampiana de que 'el espectador hace la obra', porque para él 'el espectador vive la obra', porque el sentido conceptual de la misma no sólo se debe buscar en la indagación de sus causas, sino también buscar las causas en sus efectos.

En fin, en este sentido, esperamos haber iluminado —aunque pobremente- una visión diversa, menos condicionada y más vivencial, de la obra de un Oiticica que representa de tal manera el experimento de lo experimental y la postura ético-creativa marginal, que su nombre —o la simplificación y el empobrecimiento analógico de considerarlo el 'Warhol brasileño' - es suficiente para que cualquiera de sus obras acabe a priori clasificada, para bien o para mal. Analógicamente diríamos que el mecanicismo obra-autor opera en paralelo con aquello que podemos denominar el 'efecto Frankenstein', es decir, con el hecho de existir una clara y paradójica confusión mecanicista entre el creador y 'padre' del monstruo, el sabio loco Víctor Frankenstein, y su criatura anónima, el antropoide gigante creado a partir de fragmentos de cadáveres humanos.

La obra de Hélio, constatada y contestada, es también una obra para ser leída, porque tuvo la virtud de plantear todas las cuestiones, incluso cuando, no raramente, las pudo duchampianamente 'dejar sin solución por no existir los posibles problemas', y porque, en especial en la monstruosa Newyorkaises, su autor pensó y se pensó escribiendo - y escribió pensando y pensándose-, siempre de manera oblicuamente sinuosa, como si tuviese un GPS de los sentimientos contradictorios y pasionales de lo humano y, por lo tanto, se pudiese - y debiese- mostrar tan excesivo y diverso, con tantas cualidades y defectos como su propia figura de hombre y creador se lo exigía.

\section{Obras CITADAS}

Aguilar, Gonzalo. 2006. "Hélio Oiticica, Haroldo y Augusto de Campos: el diálogo velado - La aspiración a lo blanco". O eixo e a roda 13: 55-84. Web. 15 de mayo de 2019. http://www.letras.ufmg.br/poslit

Arijón, Teresa. 2013. "Ser marginal/Ser héroe. Cuaderno de Hélio". Materialismos. Por Hélio Oiticica. Buenos Aires: Manantial. 9-23. 
Ayres, Anita. 2015. "Os labirintos de Hélio Oiticica”. Usina 23. Web. 08 de nov. de 2018. https://revistausina.com/23-edicao/os-labirintos-de-helio-oiticica/

Braga, Paula Priscila. 2007. A trama da terra que treme: Multiplicidade em Hélio Oiticica. Tesis de Doctorado presentada al Programa de Pós-Graduação em Filosofia da Faculdade de Filosofia, Letras e Ciências Humanas de la Universidade de São Paulo. Web 10 out. de 2018. https://www.teses.usp.br/teses/disponiveis/8/.../TESE_PAULA_PRISCILA_BRAGA.pdf

Cámara, Mario. 2011. Cuerpos paganos. Usos y efectos en la cultura brasileña (1960-1980). Buenos Aires: Santiago Arcos editor.

Camnitzer, Luís. 2007. Conceptualism in Latin American Art: Didactics of Liberation. Austin: University of Texas Press.

Campos, Haroldo de. 1976. A operação do texto. São Paulo: Perspectiva. . (2006). Hagoromo de Zeami. 2a ed. São Paulo: Estação Liberdade.

Clark, Lygia y Oiticica, Hélio. 1998. Lygia Clark - Hélio Oiticica: Cartas 1964-74. Org. Luciano Figueiredo. Rio de Janeiro: UFRJ.

Figueiredo, Luciano. 1986. "Introdução". Aspiro ao grande labirinto. Por Hélio Oiticica. Orgs. Luciano Figueiredo, Lygia Pape y Waly Salomão. Rio de Janeiro: Rocco: 5-7.

Hollanda, Ana de. 2011. "Apresentação". Hélio Oiticica: museu é o mundo. Org. César Oiticica Filho. Rio de Janeiro: Beco do Azougue. 7.

Lucchetti, R. F. 1990. Vampirismo: o cinema em pânico. Rio de Janeiro: Editora BrasilAmérica; Fundação do Cinema Brasileiro.

Morais, Frederico. 1976, 6 de enero. "Revisão / 69-2: a nova cartilha”. Diário de Notícias [Rio de Janeiro]: s./p.

Oiticica, Hélio. 1968a. "A criação plástica em questão - respostas”. Itaú cultural - Programa Hélio Oiticica. Número de catalogación: 0159/68 [Documento dactilografiado. S./d.]. Web. 11 de nov. de 2018. http://legacy.icnetworks.org/extranet/enciclopedia/ ho/index.cfm? fuseaction=documentos $\&$ cd_verbete $=4425 \& \operatorname{cod}=120 \&$ tipo $=2$ . 1968b. “'Sêco 27’ /guache sobre cartão”. Itaú cultural - Programa Hélio Oiticica. Número de catalogación: 0439/68. [Verso del Metaesquema. Manuscrito. 13/11/1968]. Web. 11 de nov. de 2018. http://legacy.icnetworks.org/extranet/enciclopedia/ho/index.cfm?fuseaction=documentos\&cod=519\&tipo $=2$

. 1973. "S’IL ÉTAIT BIEN ÉVEILLÉ". Itaú cultural - Programa Hélio Oiticica. Número de catalogación: 0267/73 [Documento manuscrito. 24/06/1973]. Web. 2 de nov. de 2018. http://legacy.icnetworks.org/extranet/enciclopedia/ho/index. cfm?fuseaction=documentos $\&$ cd_verbete $=4366 \& \operatorname{cod}=19 \&$ tipo $=21$

. 1974a. "Carta a Waly". Itaú cultural - Programa Hélio Oiticica. Número de catalogación: 0151/74 [Documento dactilografiado. 23/01/1974]. Web. 2 de nov. de 2018. http://legacy.icnetworks.org/extranet/enciclopedia/ho/index. cfm? fuseaction $=$ documentos $\&$ cd_verbete $=4382 \& \operatorname{cod}=516 \&$ tipo $=2$

. 1974b. "Lendo Gertrude Stein". Itaú cultural - Programa Hélio Oiticica. Número de catalogación: 0351/72. [Documento manuscrito (0351/74)]. Web. 25 
de jun. de 2019. http://legacy.icnetworks.org/extranet/enciclopedia/ho/index. $\mathrm{cfm}$ ?fuseaction $=$ documentos\&cd_verbete $=4486 \& \operatorname{cod}=491 \&$ tipo $=2$ . 1980. "Entrevista com Hélio Oiticica". Itaú cultural - Programa Hélio Oiticica. Número de catalogación: 0059/80. [Anexos. Adenda de la entrevista. Datilografiado en 14/02/1980] Web. 11 de nov. de 2018. http://legacy.icnetworks.org/extranet/enciclopedia/ho/index.cfm?fuseaction=documentos\&cod $=76 \&$ tipo $=2$ . 2009. Hélio Oiticica. Org. César Oiticica Filho y Ingrid Vieira. Rio de Janeiro: Beco do Azougue.

Oiticica Filho, César. 2011. "Introduçáo" Hélio Oiticica: museu é o mundo. Org. César Oiticica Filho. Rio de Janeiro: Beco do Azougue. 16. 